\title{
Evaluation of VIIRS, GOCI, and MODIS Collection 6 AOD retrievals against ground sunphotometer observations over East Asia
}

\section{Q. Xiao et al.}

Correspondence to: Y. Liu (yang.liu@emory.edu)

The copyright of individual parts of the supplement might differ from the CC-BY 3.0 licence. 


\section{$1 \quad$ Text S1.}

2 The Microtop II handheld sunphotometer AOD measurements were compared against

3 AERONET measurements within $6 \mathrm{~km}$ of the handheld sunphotometer measuring

4 sites. The slope, intercept, and $\mathrm{R}^{2}$ of the linear regression between Microtop II

5 measurements and average hourly AERONET measurements during the satellite

6 overpass time $(1: 00 \mathrm{pm}-2: 00 \mathrm{pm})$ were $0.95,0.16$, and 0.64 , respectively $(\mathrm{N}=74)$. 
1 Figure S1. Buffers used in the temporal and spatial comparisons for each satellite

2 aerosol product. The yellow dashed line denotes the $3 \mathrm{~km}$ grid and the white dashed

3 line denotes the $6 \mathrm{~km}$ grid. The temporal comparison figure (left) shows the $3 \times 3$ grid

4 cells buffer for MODIS (pink), VIIRS EDR and GOCI products (blue), as well as the

51 grid cell buffer for VIIRS IP product (green); the spatial comparison figure (right)

6 shows the 1 grid cell buffer for each sensor.
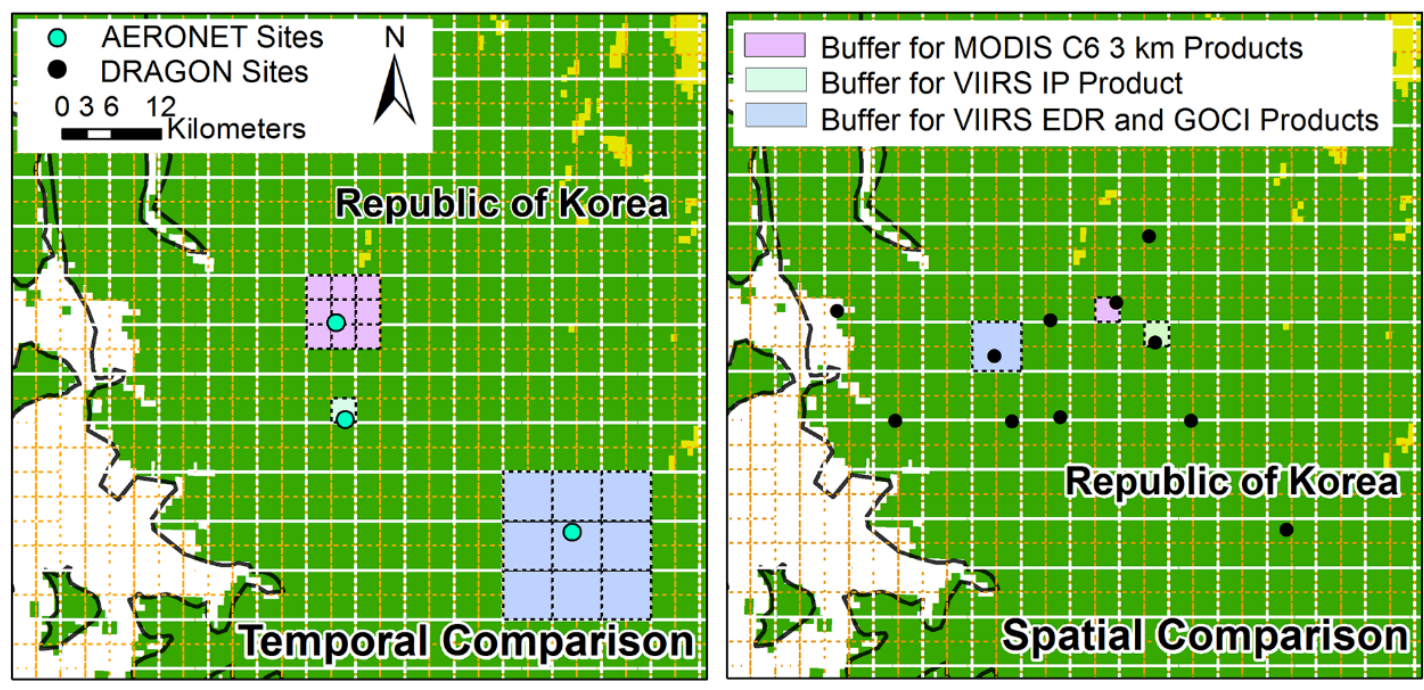
1 Table S1. Statistics of normality tests of residuals from linear regressions for temporal

2 comparisons between satellite retrievals and ground AOD measurements at $550 \mathrm{~nm}$

3 over Japan-South Korea region.

\begin{tabular}{lllll}
\hline Satellite & \multicolumn{2}{c}{$\begin{array}{c}\text { Original } \\
\text { Kolmogorov- } \\
\text { Smirnov p-value }\end{array}$} & Skewness & $\begin{array}{c}\text { Log-transformed } \\
\text { Kolmogorov- } \\
\text { Smirnov p-value }\end{array}$ \\
\hline VIIRS EDR & 0.72 & $<0.01$ & -0.43 & $<0.01$ \\
VIIRS IP & 1.31 & $<0.01$ & 0.10 & $<0.01$ \\
GOCI & 0.81 & $<0.01$ & -2.40 & $<0.01$ \\
GOCI all obs. & 0.63 & $<0.01$ & -1.75 & $<0.01$ \\
Aqua MODIS C6 3 km & 1.85 & $<0.01$ & 0.25 & $<0.01$ \\
Terra MODIS C6 3 km & 1.24 & $<0.01$ & 0.76 & $<0.01$ \\
\hline
\end{tabular}

4 
1 Table S2. Percent coverage of satellite aerosol products relative to AERONET stations

2 in Beijing and over East Asia.

\begin{tabular}{lll}
\hline Product & \% coverage in Beijing & \% coverage over East Asia \\
\hline VIIRS_EDR & 41 & 63 \\
VIIRS_IP & 42 & 50 \\
GOCI & 73 & 74 \\
GOCI all obs. & 60 & 27 \\
Aqua MODIS C6 $3 \mathrm{~km}$ & 38 & 24 \\
Terra MODIS C6 $3 \mathrm{~km}$ & 40 & 26 \\
\hline
\end{tabular}

3 
1 Table S3. Statistics of the temporal comparison between satellite retrievals and

2 AERONET AOD at $550 \mathrm{~nm}$ over East Asia, including all the coincident satellite-

3 ground AOD pairs.

\begin{tabular}{lllllll}
\hline & $\mathrm{N}$ & $\mathrm{R}^{2}$ & Slope & Intercept & Bias & \%EE \\
\hline VIIRS EDR & 800 & 0.69 & 0.94 & 0.08 & 0.07 & 61 \\
VIIRS IP & 615 & 0.47 & 1.00 & 0.17 & 0.17 & 35 \\
GOCI & 442 & 0.77 & 1.03 & 0.03 & 0.04 & 54 \\
GOCI all obs. & 3524 & 0.80 & 1.01 & 0.01 & 0.01 & 60 \\
MODIS Aqua C6 & 308 & 0.71 & 1.03 & 0.07 & 0.08 & 55 \\
MODIS Terra C6 & 351 & 0.65 & 1.04 & 0.14 & 0.15 & 41 \\
\hline
\end{tabular}

4 
1 Table S4. Statistics of comparisons between VIIRS IP retrievals with both high and

2 degraded quality against ground AOD measurements over the Japan-South Korea

3 region.

\begin{tabular}{llllllc}
\hline Ground Measurements & $\mathrm{N}$ & $\mathrm{R}^{2}$ & Slope & Intercept & Bias & $\% \mathrm{EE}$ \\
\hline AERONET & 654 & 0.42 & 0.99 & 0.20 & 0.20 & 30 \\
DRAGON & 271 & 0.48 & 0.98 & 0.31 & 0.30 & 27 \\
\hline
\end{tabular}

4 
1 Table S5. Statistics of the temporal comparison between GOCI retrievals and

2 AERONET AOD measurements over East Asia, stratified by time.

\begin{tabular}{lllllll}
\hline Local Time & $\mathrm{N}$ & $\mathrm{R}^{2}$ & Slope & Intercept & Bias & \%EE \\
\hline 9:00 & 402 & 0.82 & 1.00 & 0.00 & -0.002 & 68 \\
$10: 00$ & 342 & 0.82 & 1.05 & 0.01 & 0.024 & 69 \\
$11: 00$ & 307 & 0.80 & 1.02 & 0.02 & 0.031 & 64 \\
$12: 00$ & 286 & 0.78 & 0.98 & 0.04 & 0.029 & 62 \\
$13: 00$ & 317 & 0.80 & 1.02 & 0.04 & 0.045 & 61 \\
$14: 00$ & 328 & 0.83 & 1.03 & 0.02 & 0.033 & 64 \\
$15: 00$ & 317 & 0.88 & 1.06 & -0.02 & -0.004 & 72 \\
$16: 00$ & 248 & 0.87 & 0.97 & -0.03 & -0.043 & 68 \\
\hline
\end{tabular}

3 
1 Table S6. Statistics of the temporal comparison between eight GOCI hourly retrievals

2 with various quality against AERONET AOD measurements over the Japan-South

3 Korea region.

\begin{tabular}{llcccccc}
\hline \multicolumn{1}{c}{ Quality criteria } & Coverage & $\mathrm{N}$ & $\mathrm{R}^{2}$ & Slope & Intercept & Bias & $\% \mathrm{EE}$ \\
\hline Quality Flag=3 & $27 \%$ & 2547 & 0.82 & 1.02 & 0.01 & 0.02 & 66 \\
Quality Flag=2,3 & $38 \%$ & 3677 & 0.74 & 1.02 & 0.02 & 0.03 & 59 \\
Quality Flag=1,2,3 & $42 \%$ & 4058 & 0.71 & 1.01 & 0.04 & 0.04 & 57 \\
Quality Flag=0,1,2,3 & $51 \%$ & 4923 & 0.54 & 0.93 & 0.11 & 0.08 & 48 \\
\hline
\end{tabular}

4

5 
1 Table S7. Statistics of the temporal comparisons between satellite retrievals and ground

2 AOD measurements at $550 \mathrm{~nm}$ over Japan-South Korea region, with and without log3 transformation.

\begin{tabular}{llllllll}
\hline & \multicolumn{3}{c}{ Original } & \multicolumn{4}{c}{ Log-transformed } \\
& $\mathrm{N}$ & $\mathrm{R}^{2}$ & Slope & Intercept & $\mathrm{R}^{2}$ & Slope & Intercept \\
\hline VIIRS EDR & 600 & 0.74 & 0.96 & 0.06 & 0.60 & 0.77 & -0.07 \\
VIIRS IP & 424 & 0.55 & 1.03 & 0.14 & 0.50 & 0.69 & -0.01 \\
GOCI & 317 & 0.80 & 1.02 & 0.04 & 0.66 & 0.91 & -0.01 \\
GOCI all obs. & 2547 & 0.82 & 1.02 & 0.01 & 0.66 & 1.00 & -0.01 \\
Aqua MODIS C6 3 km & 179 & 0.71 & 1.00 & 0.08 & 0.68 & 0.90 & 0.03 \\
Terra MODIS C6 3 km & 197 & 0.70 & 1.06 & 0.14 & 0.60 & 0.74 & 0.03 \\
\hline
\end{tabular}
4

5 